\title{
Hybrids and the Boundaries of Moral Considerability or Revisiting the Idea of Non-Instrumental Value
}

\author{
Magdalena Holy-Luczaj ${ }^{1}$ (D) - Vincent Blok ${ }^{2}$
}

Received: 4 March 2019 / Accepted: 3 October 2019/ Published online: 5 November 2019

(C) The Author(s) 2019

\begin{abstract}
The transgressive ontological character of hybrids - entities crossing the ontological binarism of naturalness and artificiality, e.g., biomimetic projects - calls for pondering the question of their ethical status, since metaphysical and moral ideas are often inextricably linked. The example of it is the concept of "moral considerability" and related to it the idea of "intrinsic value" understood as a non-instrumentality of a being. Such an approach excludes hybrids from moral considerations due to their instrumental character. In the paper, we revisit the boundaries of moral considerability by reexamining the legitimacy of identifying intrinsic value with a non-instrumental one. We offer the concept of "functional value," which we define as a simultaneous contribution to the common good of the ecosystem and the possibility to disclose the full variety of aspects of a being's identity. We argue that such a value of hybrids allows us to include them into the scope of moral considerability.
\end{abstract}

Keywords Hybrids · Moral considerability · Instrumental value · Intrinsic value · Functional value $\cdot$ Environmental ethics

\section{Introduction}

In our environment today, one can find ever increasing numbers of hybrids-entities that straddle the boundary between naturalness and artificiality. This transgressive

Magdalena Holy-Luczaj

m.holy.luczaj@gmail.com

Vincent Blok

vincent.blok@wur.nl

1 Department of Social Sciences, University of Information Technology and Management in Rzeszow, Sucharskiego 2, 35-225 Rzeszow, Poland

2 Philosophy Group, Wageningen University and Research Centre, De Leeuwenborch (Building 201), Room 5060, Hollandseweg 1, 6706 KN Wageningen, Netherlands 
ontological character of hybrids calls for pondering the question of their ethical status, since metaphysical and moral ideas are often inextricably linked (Brennan and Lo 2010, pp. 104-107; Thomson 2004; Howe 1993; Callicott 1986). A good example of this type of consideration is the concept of "moral considerability" developed originally in the field of environmental philosophy, which defines what kinds of beings deserve moral attention on the basis of their ontological features (Horta 2018; Hale 2011; Goodpaster 1978). There is a common agreement among environmental ethicists that moral considerability should be restricted to the set of natural beings, but the very existence of hybrids, which can transcend the categories of nature and technology, may spur us to revisit the scope of moral considerability. Considering that the current development of science and technology leaves no doubt that the frequency of dealings with hybrids will only increase, there is a need to determine their particular moral considerability.

We argue for the ethical upgrade of hybrids and their inclusion among other morally considerable entities. This will require a reevaluation of the idea of intrinsic value as a non-instrumental one - as well as other concepts related to it - since the instrumental character of artifacts is the rationale for excluding hybrids from the scope of moral considerability. Drawing upon the general orientation of the philosophy of technology, we argue that instrumentality (or functionality), however, does not necessarily need to be perceived through the prism of ontological inferiority, nor be seen as being trapped in the relations of supremacy and subordination, as is often the case in environmental ethics discourses. In this article, we show that hybrids can also potentially contribute to the good of other beings and the environment of planet Earth as a whole. This potential of hybrids can encourage us accept the use of high-tech solutions for fighting the ecological crisis we face today as a society.

The structure of the paper is as follows. First, we analyze the dualism of natural beings and artifacts in environmental philosophy and philosophy of technology. Second, we discuss how hybrids challenge the classical categories. We then reconstruct the debate on moral considerability and explain why artifacts were excluded from it. In the final part, we offer possible strategies of shifting the boundaries of moral considerability in order to include hybrids and sketch implications for policy practices.

\section{Dualism of Natural and Artificial Beings}

Before we answer the question whether hybrids deserve moral considerability, we need to take a step back and look at how artifacts, or rather the dualism of natural beings and artifacts, is typically ${ }^{1}$ perceived in environmental ethics.

In short, environmental ethicists categorize artifacts as ontologically inferior compared to natural beings. They do so in accordance with Aristotle, who claimed in his Physics that substances are individual objects, but not all individual objects are substances. For instance, Aristotle declined the status of substances to artifacts, even though they are single, material beings. According to him, artifacts (which he defined

\footnotetext{
${ }^{1}$ There were, of course, significant exceptions, such as Andrew Light, who challenged strong rejections concerning ecological restoration as unhelpful (Light 2009) or Steven Vogel's attempts to bring attention to the unfair status of artifacts in environmental ethics (Vogel 2015, 2003).
} 
as "created things") are not genuine substances because, in contrast to natural beings ("growing things"), they do not have the principle of origin of the movement in themselves, since this principle is located in mankind as their creator. The vast majority of environmental philosophers accept these Aristotelian claims today, continuing to contrast artifacts with natural beings in contemporary ethical reflections.

Before we will discuss this, we should specify that the artifacts in question are technological objects. The set of artifacts includes also works of art, as well as religious, historic, or heritage objects. The difference between the latter and technological objects will be of more importance, however, when we will analyze the issue of non-instrumentality. In what follows, we reconstruct the way the majority of environmental ethicists contrast natural beings and technological artifacts, because these are the latter that usually serve as the point of reference to highlight the uniqueness of nature.

First, environmental philosophers point out, and this is essential for their argument, that artifacts are created by human beings. That is to say, artifacts do not have the origin of the movement in themselves. It is a human decision that they come into existence (Katz 1993, 229; Siipi 2003, p. 416). This is however not a sufficient condition for an entity to be an artifact. For instance, children are often deliberately brought into existence and yet, they are not artifacts (Siipi 2003, pp. 416-417). It is due to another essential aspect of artifacts: they have determined functions, which, moreover, are always related to human needs (Lee 1999, p. 73; see Katz 2018, 1993).

This characteristic is assessed as negative-because of fixed specific functions artifacts are thought to have a much poorer identity compared to natural beings (both biotic and abiotic, see Katz 1993, p. 229; see Siipi 2003, p. 414). The latter cannot be described by a single function nor even by a limited number of functions. Moreover, due to this characteristic, artifacts are not as ontologically independent as natural beings are (Lee 1999, pp. 178-179; Katz 1993, p. 229). The dominant vision in environmental philosophy is that the essence of natural beings is not placed within the frame of human intentional/functional structures; natural beings do not exhibit purposiveness and enddirectedness defined by human beings as their foundations (Lee 1999, p. 73; Katz 2002, 1993). Natural beings do not (merely) serve human goals - they have their own internal telos that guides their existence, unlike artifacts, as Keekok Lee underlines in reference to Aristotle (Lee 1999, pp. 37-39). This aspect is the basis of the expression "teleological-center-of-life," coined by Paul Taylor (1986). According to this view, natural beings have the teleological-center-of-life in themselves, in contrast with artifacts, which do not have the teleological-center-of-life in themselves - this "center-of-life," or purpose has been superimposed upon them by humans.

Furthermore, environmental philosophers often claim that artifacts are not as complex as natural beings are, since they lack the ability to self-repair or self-maintain. For example, plants are capable of tissue and cell renewal, and even self-defense (Lee 1999, pp. 170-172). Environmental philosophy emphasizes that artifacts - unlike natural beings - do not strive to sustain their own functional integrity (Callicott 2005, p. 189). Artifacts are thus portrayed not only as if they lack any interests of their own - they also do not "care" about their being. In this manner, as some environmental philosophers hold, artifacts are similar to abiotic nature (Lee 1999, p. 172; Goodpaster 1980 , p. 282; Murray 1980, p. 61). Yet, the latter belongs to the natural order and hence, its ontological status is not as low as that of artifacts for the abovementioned reasons (see Naess and Sessions 1995, p. 50; Birch 1993, p. 331). 
Another difference between natural and artificial entities is that artificial ones are described as secondary to the natural material from which they were made. For example, a tree is not a derivative of wood - a tree is wooden - but a wooden chair is. Of course, there are degrees of artifacticity in this regard. Material can be natural (e.g., wood) or derived from natural material (e.g., plastic as made from oil), or constructed de novo (e.g., diamondoid material).

Summing up, according to environmental philosophers, artifacts' ontological dependence is twofold: on the one hand, it is anthropocentric - in the sense that their telos is humanly imposed and oriented toward human needs, and second anthropogenicbeing created by humans. The latter claim implicitly contains another characteristic of natural beings which artifacts do not share: the first are able to self-reproduce, while artifacts are not. ${ }^{2}$

We can see that technological artifacts are contrasted not only with living beings but also generally with all natural ones. The problem of life (or divide living/non-living) will return in the Section 4. For the moment, to keep our argument clear, we compare the differences between natural and artificial beings, as perceived by environmental philosophy, in the table below (Tables 1, 2, and 3).

Interestingly, philosophy of technology presents descriptively quite similar views on artifacts, but normatively, it takes quite different position, because its representatives do not claim that artifacts are inferior to natural beings. In philosophy of technology, or more precise, philosophy of artifacts, a reformulation of the Aristotle's view on the essence of artifacts is inseparably connected to human being can be found, namely in the assumption that artifacts are not only physical things, but also mind-dependent (intentional) objects (Franssen, 2008; Baker 2009). That is to say, artifacts have two dimensions of identity. Technical artifacts remain physical objects that are subject to the laws of nature like any other material object in the universe, but additionally, unlike ordinary natural objects, their being created "for a purpose" gives them an intentional "side" (Franssen 2008).

The intentionality of artifacts is actually identical to their functionality, which is seen as their primary characteristic (Houkes and Vermaas 2009, p. 123; Kroes and Vermaas 2008, p. 76). As Houkes and Vermaas (2009, p. 124) point out, a large number of artifacts are even named in functional terms, such as "screwdriver" (see Baker 2009, p. 9). This functionality (or intentionality) can, however, be divided into two stages: the intentionality involved in the design and in the use of the artifact (Lawson 2008). It is not a rare case when something is produced to serve a different purpose than it later actually has. Examples can be a tire made into a garden swing or dynamite which was later used for another purpose than it was initially developed for. This divide between intentionality of the design and its use does not yet change the fact that the functional/ intentional aspect is something what is supposed to distinguish artifacts from the rest of the physical objects in the philosophy of technology.

Summing up, according to philosophers of technology, artifacts are different than natural beings, but it does not mean that they should be kept in low metaphysical regard. The functionality of artifacts is something what we should be positive about.

\footnotetext{
${ }^{2}$ This discussion as well as the table below can be compared with our previous presentation of the status of artifacts according to environmental philosophy, in which we focused on the differences in how environmental philosophy and philosophy of technology have portrayed artifacts (see Holy-Luczaj and Blok 2019).
} 
Table 1 Comparison of natural and artificial beings according to environmental philosophy

\begin{tabular}{|c|c|}
\hline Natural beings & Artificial beings \\
\hline Self-created & Created by human beings \\
\hline $\begin{array}{l}\text { Able to self-reproduce, self-preserve, self-maintain, } \\
\text { and heal themselves }\end{array}$ & $\begin{array}{l}\text { Unable to self-reproduce, self-preserve, self-maintain, } \\
\text { and heal themselves }\end{array}$ \\
\hline Variety of functions independent from human goals & Specific functions, all related to human purposes \\
\hline Original identity in terms of their substance & Secondary to the material they are made of \\
\hline
\end{tabular}

This will be of particular importance later, but before we will discuss that, in the next section, we show how hybrids undermine the binarism of natural and artificial and present their classification.

\section{The Hybrids}

We employ the term "hybrids" to refer to beings that combine natural and artificial elements as well as functions, which traditionally are seen as belonging to two binary categories. In this sense, hybrids constitute a new type of being, in which parts from different domains become inextricably linked and form a separate ontological class. What is worth clarifying is that we find hybrids in this sense only among relatively recent technological developments.

The internal diversity of hybrids however calls for some categorization. We explored this issue elsewhere and proposed a classification of hybrids based on two tendencies observed in current advances in technology and innovation: technologizing (artificializing) nature and naturalizing technology. We have established two categories of hybrids in accordance with the tendencies indicated above: (1) bio-augmented projects (result of technologizing nature) and (2) bio-mimetic projects (naturalizing technology), each with three subcategories. ${ }^{3}$

(1) Bio-augmented projects consist of organisms whose predecessors were regular natural beings, but who become themselves significantly different than past generations due to human intervention and design. An example can be a genetically modified cow, which produces human-like milk to feed newborn humans. It is essential to highlight that genetic modification is not the same kind of human intervention in nature as classical breeding. For instance, thanks to GM technologies, human beings are able to import traits from any living being - breeders are no longer restricted to working with close relatives. This is clearly a huge leap (Kingsbury 2009, pp. 399, 409). Thus, we argue that unlike bred animals, GM organisms are not fully natural beings anymore - they are hybrids in the sense that they can be classified as "bio-augmented projects," that is, augmented organisms.

\footnotetext{
${ }^{3}$ We employ the term "projects," because it refers to the human ability and willingness to design things, which can be seen as complementary to biological design. Another reason for doing so is that the "pro-ject" is somewhere in between the "subject" and "object" - as neither fully ontologically autonomous nor totally dependent on its creator.
} 
Table 2 Classification of hybrids

Hybrids

\begin{tabular}{|c|c|c|c|c|c|}
\hline \multicolumn{3}{|c|}{ Bio-augmented projects } & \multicolumn{3}{|c|}{ Bio-mimetic projects } \\
\hline \multirow[t]{2}{*}{ Fertile } & Sterile & & Bioreplacements & Biomimetic beings & \\
\hline & $\begin{array}{l}\text { With a } \\
\quad \text { (strengthened) } \\
\quad \text { original function }\end{array}$ & $\begin{array}{c}\text { With a new } \\
\text { function }\end{array}$ & & $\begin{array}{l}\text { Weakly } \\
\text { bio-mimetic }\end{array}$ & $\begin{array}{l}\text { Strongly } \\
\quad \text { bio-mimetic }\end{array}$ \\
\hline
\end{tabular}

The primary trait that qualifies them as artifacts is that they are designed for a very particular purpose invented by humans. The difference between traditional bred animals and bio-augmented projects is that genetic modification gives breeders the precision that they have always wanted but could not achieve. New species have precise, specific capacities, which human beings needed from them: they are more resistant, more effective, giving particular types of foods, etc. They are more functional or more specialized in some functions than their predecessors, and functionality, as we have seen, is one of the core characteristics of artifacts. GMOs are thus more predictable than their natural counterparts, and as such, they lose much of their ontological autonomy. The functional aspect, however, is quite varied among augmented organisms, and therefore, we suggest dividing them into two further subcategories, namely one in which a function inherent to the organism has been enhanced (e.g., plants that are modified to be more resistant to certain diseases or the already mentioned cow producing a specific type of milk), and one consisting of augmented organisms, which due to the human intervention, has gained completely new functions compared to their predecessors. An example in this category could be bio-luminescent trees, which illuminate city-center streets (Krichevsky et al. 2019). In such a case, a tree becomes a "natural" replacement of technological objects (street lamps) due to having been bred with a new trait not inherent to ordinary trees, i.e., the ability to emit light.

Limiting the classification to the above, however, would not give us a broad enough picture of bio-augmented projects; we might be inclined to reduce GMOs to artifacts due to seeing only their functional aspects. It is important to remember

Table 3 The scope and criteria of moral considerability in environmental ethics

\begin{tabular}{|c|c|c|}
\hline Stance & Scope & Criterion \\
\hline "Land ethic" & $\begin{array}{l}\text { Bio-community as a whole (wild nature, } \\
\text { exclusion of domesticated animals } \\
\text { and farm) }\end{array}$ & Constituting the "original" ecosystem \\
\hline $\begin{array}{l}\text { Animal rights } \\
\text { activists }\end{array}$ & Animals & Sentiency \\
\hline Biocentrists & All living beings (animals, plants) & $\begin{array}{l}\text { Being an organism that is a "teleological } \\
\text { center of life" }\end{array}$ \\
\hline Ecocentrists & $\begin{array}{l}\text { All particular, natural beings (including } \\
\text { inanimate nature) }\end{array}$ & Being a "flourishing" entity \\
\hline
\end{tabular}


that such hybrids are still organisms: they are able to self-maintain, grow, selforganize, and self-regenerate like natural beings. For instance, GM cows and trees self-develop (from egg cell or seed to a mature being) and are able to heal themselves if hurt. These characteristics are clearly linked with natural beings. What is also of significant importance is that some GMOs-under a few conditions - can reproduce themselves (e.g., some GM seeds) and/or fertilize their regular/natural counterparts (Van Acker et al. 2017; Robaey 2016). This ability to self-reproduce can be a basis for a further divide of this category: sterile and fertile bio-augmented projects.

(2) The other category of hybrids-bio-mimetic projects - basically embraces artificial entities that try to follow natural solutions. This peculiarity consists then not in the natural origin of the material they are made of (as it is in the case of traditional artifacts, such as a wooden chair), but rather in the fact that they substitute natural functions or integrate such functions in their modus operandi. This variety, again, demands division into subcategories.

The first subcategory of bio-mimetic projects - bio-replacements - is actually the "contraposition" of the subcategory of bio-augmented projects with a new function: it includes "technological" beings, which are designed to replace natural ones. That is to say, these two subcategories are "complementary opposites" since they have equally high aspirations but are oriented in two different directions and originate from two different sides. Bio-augmented projects with completely new functions derive from nature and move toward the technological pole to serve typically artificial functions, while bio-replacements leave the purely technological domain to serve or sustain internal, natural functions of some organism.

Bio-replacements can be found in bionics, in which electronic devices and mechanical parts are integrated in the human body, or more recently, a synthetic cell. The latter is an engineered particle that mimics one or many functions of a regular biological cell and was designed to directly substitute it. The synthetic cell is yet not completely artificial, because it consists of some natural components and is in some cases able to replicate, which makes them quite "natural." On the other hand, it was designed by human beings and is therefore much more controllable than natural cells (Xu et al. 2016).

Another category of bio-mimetic projects includes biomimetic entities. According to the proponents of biomimicry, it introduces a new and ecosystemfriendly approach to nature, which is no longer characterized by the domination and exploitation of nature, but rather by learning and exploration (Benyus 2002). We can distinguish two approaches here, which we can refer to as a "weaker concept of biomimicry" and a "stronger concept of biomimicry" (Blok and Gremmen 2016, p. 205). They both provide a perfect ground for creating hybrids, yet the first bases itself and improves upon a natural technology, whereas the second is an artificial technology inspired by a natural process/organism.

The weaker concept sees mimicry not as the duplication of natural solutions, but primarily as a creative solution inspired by nature. For this reason, some scholars refer to it as to "bio-inspiration" (Rajeshwar 2012, p. 3). According to this approach, some artifacts, while inspired by nature, aim to be more "perfect" (again - according to human needs) than nature itself. They keep what is valuable from an original natural form or process and try to reduce all weaknesses. An 
example of this subcategory can be found in a solar cell inspired by a leaf or a car design inspired by the way trees and bones optimize their strengths and materials. We can say that such devices perform a secondary imitation of nature. For instance, unlike a hammer or a shovel, the creation of which was directly inspired by the possibilities of the fist or the open hand respectively; biomimetic car materials follow natural solutions which are not directly linked to the primary function of a car - motion - but refer to some other traits of an organism and are for example built from material resistant to various collisions. In this sense, the biomimetic car is something like a 2.0. model: its "upgrade" consists of an innovation modeled on natural solutions that make it more resistant and safer than its traditional, fully artificial counterpart (1.0. model).

The stronger concept of biomimicry, on the other hand, studies the design of natural systems and then imitates these designs to solve human problems, recognizing natural solutions as unequaled role models that should not - and actually cannot - be improved upon (Dicks 2017, p. 256; Benyus 2002). A prime example of hybrids belonging to the strong biomimetic category could be materials made with natural components (such as starch, for instance; see Avella et al. 2005) that decompose into carbon dioxide, water, biomass, etc. These biodegradable materials are more advanced than traditional artificial materials such as plastic since they have new capacities.

Other strong biomimetic hybrids are compounds of technological facilities, natural agents, and human beings, who design and manage the entire complex. One example is the air-conditioning system inspired by the structure of a termite hill. Another is a biorefinery in which bacteria, waste streams, and human operators are interconnected and form a hybrid entity (Blok and Gremmen 2016).

One more aspect of strong biomimetic hybrids should be emphasized here: "embeddedness." By "doing it the natural way", such natural technologies can claim to be better embedded in and in harmony with the natural ecosystems of planet earth (Dicks 2016, pp. 231, 236; Blok 2017; Benyus 2002). Interestingly, this opposes the GMO hybrids, which tend to go beyond the internal limitation of nature. In designing them, human beings often disrespect their inherent natural character, destroying naturally established species barriers and specific characteristics of the land (Peterson and Sandler 2008). This is another difference that clearly demonstrates the wide internal variation among hybrids.

This variety of hybrids will be investigated further in the context of moral considerability after we reconstruct key assumptions of this concept.

\section{Criteria of Moral Considerability}

Unlike classical ethics, there are two key questions for environmental ethics. It is not only a matter of how to act; the morality of our actions must also be assessed according to whom our actions affect (Gunkel 2014, p. 113). Classical ethics found it self-evident that only relations with people need to be evaluated as moral vs. amoral. Environmental ethics, in turn, claims that also our dealings with non-human natural beings should be morally assessed, or, to put it differently, non-human natural beings deserve to be 
considered morally and likewise to be treated correspondingly. This state of "deserving" is referred to as "moral considerability."

A central hypothesis for environmental ethicists is then that the scope of moral considerability in traditional ethics was not broad enough (see Gunkel and Bryson 2014, p. 6). As Andrew Light and Holmes Rolston III write, "looking at the past there is a good case to be made that ethics has often not been inclusive enough. (...) We regularly come to criticize our past for unduly restricting moral obligation to those we have now more fully brought into the moral circle, such as slaves, African-Americans, women (...)" (Light and Rolston III 2006, pp. 6-7). But the need to extend the scope of moral considerability is actually the only claim that environmental ethicists commonly agree upon - the question of how broad it should be is the key and most controversial question in the debate on moral considerability.

The father of environmental ethics, Aldo Leopold, claimed that we should morally respect nature as a whole. In accordance with such a claim, "a thing is right when it tends to preserve the integrity, stability, and beauty of the biotic community. It is wrong when it tends otherwise" (Leopold 1987). In this sense, the feature which qualifies some being to moral considerability is the ability to affect ecosystems (this approach was thus referred to as "the land ethic"). Yet, one of its most prominent representatives, J. Baird Callicott, decided to narrow morally considerable beings down to the "original," that is the wild, biotic community, to which farm and domestic animals are not included (Callicott 1980, 1988). This formed one of the key controversies between J. Baird Callicott and Peter Singer and Tom Reagan. Singer and Reagan disapproved of Callicott's view, arguing that moral considerability should be granted to farm animals as well, since they are equally sentient - are able to suffer/feel pain - to wild animals (Singer 1975; Regan 1983). The shift they made was oriented toward individual good, which can be morally assessed in terms of causing or reducing the suffering of some being. According to them, the scope of moral considerability should then be defined by sentiency.

Some theorists found this criterion to be too restrictive and also included, e.g., plants into the domain of moral considerability as living beings_-prioritizing their selfdirectness and defining them with an already mentioned term "teleological-centersof-life" (Goodpaster 1978, pp. 316-325; Taylor 1986). When moral considerability is granted to all animate beings, the criterion determining the wrongness or rightness of

\footnotetext{
${ }^{4}$ The idea of moral considerability is basically complementary to the concept of "moral patiency" as distinct from "moral agency." The class of moral "patients" (receivers of the action) is the class of beings to whom we consider that we owe ethical obligations, whereas moral "agents" (originators of the action) are defined as that class of moral patients, usually only persons, to whom we owe obligations and who, in turn, are held to be morally responsible for their actions. What is of significant importance is that this distinction assumes that all moral agents are moral patients, but not all moral patients are moral agents. Likewise, beings that can be granted moral considerability do not need to (be able to) morally consider their own actions (see Light and Holmes Rolston 2006, p. 6; Gunkel, Bryson 2014, p. 5). Interestingly, we can however think of AI agents as moral agents (e.g., if they regulate their actions and decisions by some kind of ethical reasoning system) who, however, are not moral patients - e.g., if not considered sentient or as having their own inherent moral interests. This however will require another paper to discuss such a possibility. To complicate further the picture of moral considerability, we can distinguish it from moral significance and moral relevance (Hale 2011), but for the subject of our paper such distinctions are not essential, even though there are many cases when they are very useful.
} 
our behavior vis-à-vis these organisms is to what extent we limit their ability to fulfill their intrinsic end, or telos.

Another group of environmental philosophers took a step further and argued for the moral considerability of inanimate natural beings as well (rocks, mountains, rivers), insofar as they belong to the sphere of phusis or natural order (Naess and Sessions 1995, p. 50; Brennan 1988). They advocate a broader use of the term life (for instance, as "flourishing," see Naess and Sessions 1995) for which they can find supporters among scientists' who show that the boundaries of animate and inanimate nature are more and more often considered blurred or imaginary (see Annila, Kolehmainen 2015). So, if being a natural individual is the criterion to grant moral considerability to an entity, we assess behavior as morally correct or incorrect depending on whether it interferes or helps maintain its existence and integral identity.

This array of various positions shows the possible breadth of moral considerability in the field of environmental ethics. However, we need to bear two things in mind. First, these stages of the debate on limits of moral considerability are not chronological, in the sense that it is still an ongoing debate (Holy-Luczaj 2020; Horta 2018; Hale 2011). Second, ethical extensionism does not imply an ethical egalitarianism: that is to say, ascribing moral considerability to an extended group of beings does not imply that the well-being or interests of each of its sub-groups will be considered to be equally important. For instance, accepting the claim that plants deserve to be morally considered does not necessarily result in the thesis that their life is as significant as the life of animals. Currents in environmental philosophy that advocate including all natural beings (animate and inanimate) into the circle of moral considerability and support the equity of their life and existence are classified as "radical." This is the case in the deep ecology movement, whose representatives advocate, for instance, the moral considerability of rocks or rivers because they - appealing to a broader definition of being alive - can be seen as "flourishing" (Devall 1995, p. 15).

However, even such radical approaches limit moral considerability to natural beings - artifacts are largely excluded from any ethical considerations by environmental philosophy ${ }^{5}$ (see Gunkel and Bryson 2014, p. 6; Gunkel 2014, p. 119; Floridi 2013, p. 64; Floridi 2008; Torrance 2008, p. 502). The philosophy of technology attempts to go beyond these limitations and offers new interesting approaches like Floridi's Information Ethics or Gunkel's vindication of the rights of machines. Luciano Floridi extends the criterion of having existence, which can be impoverished or destroyed, to all entities understood informationally that results in taking into consideration all artifacts (Floridi 2013, 2008). David Gunkel, in turn, concentrates on robots and AI (Gunkel 2014, pp. 118-122, 2012, pp. 93-158).

In what follows, we will approach the problem of moral considerability of hybrids from yet another angle. We will discuss the main reason for excluding artifacts from moral considerability by environmental ethics and by revisiting it we will provide our own argument for extending the boundaries of moral considerability.

\footnotetext{
${ }^{5}$ Even the "universal consideration" stance, represented by Thomas Birch, which assumes that we should take "everything" into consideration, eventually limits its questioning to "nature" (Birch 1993).
} 


\section{Ethical Exclusion of Artifacts}

The argument of Andrew Brennan is emblematic for the situation of artifacts in environmental ethics. On the one hand, he convincingly supports taking non-living beings into ethical consideration (Brennan 1988, p. 140), ${ }^{6}$ but on the other hand, definitely distinguishes artifacts from natural beings in this respect (Brennan 1984, pp. 41-44). The basis for this distinction is that the former are functional objects (with an externally imposed telos by human beings), while the latter cannot be defined in terms of specific functions for the reasons discussed in Section $1 .^{7}$

This divide based on functionality is linked directly with the concept of intrinsic value, which is defined primarily as a non-instrumental value. According to this approach, an object has instrumental value insofar as it is a means to some goal of another being, which is dictated by that being. ${ }^{8}$ That is to say, instrumentally valued objects only have a value in use by other beings. By contrast, an object has intrinsic value if it is an end in itself or, to put it differently, has intrinsic value beyond instrumental usefulness for the limited purposes of human and other beings (O'Neill 2002, p. 131; see Naess 1984; Katz 2002).

Because the intrinsically valuable is that which is good as an end in itself, it is commonly agreed that a thing's possession of intrinsic value generates a prima facie direct moral duty on the part of moral agents to protect it or at least refrain from damaging it (Zimmerman 2014). That is to say, agents possessing a good of their own independent of being useful for other beings - entitles them to be morally considered (Brennan and Lo 2015). Since artifacts-being functional things per se-lack this intrinsic value, we allow ourselves to be indifferent toward them, imposing no constraints from an ethical perspective. They are "mere" things (Murray 1980).

This binarism is related to the argumentation that encourages human beings to respect and appreciate nature for its quality of intrinsic value, which environmental ethics describes by contrasting it with the domain of artificiality. Natural beings are not ontologically subordinated to human beings, unlike artifacts, which are created by human beings solely for the purpose of serving their needs and whims. One can argue, however, that such an attitude toward artifacts can have negative consequences insofar

\footnotetext{
6 "It might be objected that genuine concern for the continued existence, or maintenance, of an item is no evidence that such an item is morally considerable or a possessor of any kind of moral value. But suppose, my concern shows all the seriousness that is sometimes taken as the hallmark of the moral: my deliberations and actions are constrained in an especially compelling way by concern that the item in question be preserved, be left undisturbed, or be maintained in a certain condition. Argument is now needed to show that my concern here is not moral, that the item is not receiving moral consideration from me, and that the item does not therefore possess moral value.” (Brennan 1988, p. 140)

${ }^{7}$ One follower of Birch's universal stance-Benjamin Hale - who interestingly develops this concept as the "deontological approach" is of a different opinion. Unlike Birch, he excludes artifacts from moral considerations explicitly and comments on that, referring to the fact that the production of artifacts requires the use of natural resources (Hale 2011, p. 50).

${ }^{8}$ We have to remember, however, that such instrumentality (or intentionality) can be divided into two stages: the intentionality involved in the design and that involved in the use of the artifact (Lawson 2008). It is not rare for something to serve a different purpose than that for which it was initially produced. Examples can be a tire made into a garden swing or dynamite which was later used for another purpose that was initially predicted. This divide between intentionality of design and use, however, does not change the fact that the functional/ intentional aspect is something that is supposed to distinguish artifacts from the rest of the physical objects in the philosophy of technology (see Holy-Luczaj and Blok 2019).
} 
as it does not encourage people to care for them. This becomes especially questionable in the light of the fact that the majority of people are surrounded by artifacts each daybuildings and useful things - and not by pure nature, to which environmental ethics exclusively grants moral considerability (see Vogel 2015, p. 2). How moral is it to not care about our immediate surroundings?

To reinforce this question, we can think of birds' nests, otter's, and beaver's dams, which we know as entities that should not be damaged or destroyed (and this is reflected in local and national planning, regulations, etc.) and at the same time can be considered artifacts (and not merely a marginal case of them as some scholars claim (see Siipi 2003, p. 427)). They do not have their origin in themselves, but were created purposefully to serve specific functions. The difference lies in that they are not related to human needs, but respectively to that of a bird, otter, or beaver. So is this lack of interest in human artifacts related to some misanthropy? This question will return in Section 7.

In what follows, we will unpack in more detail the criteria that determine moral considerability, asking about the possibility of applying them to (various types of) hybrids, given the fact that hybrids always constitute a mix of natural and artificial elements. The key task will be to revisit the idea of functionality.

\section{Functional Value}

Summarizing what has been argued so far, many writers within the environmental philosophy tradition unequivocally maintain that technological artifacts cannot be included in the domain of moral considerability since they do not have an intrinsic value (good of their own), merely serving human purposes (possessing only instrumental value). They abstain from considering other kinds of artifacts - such as items collected in a museum, related to religions, or simply souvenirs - as they can have religious, historic, or sentimental value, which is significantly different from instrumental (utility) value that characterizes technological objects (see Hargrove 2012, pp. 178-179). But what about a separate class of beings, neither natural nor artifactshybrids? Two argumentative strategies would be most possible in this case.

(1) First, having specific functions excludes them from the domain of moral considerability. Period.

(2) Second, despite having fixed functions, hybrids inherit moral considerability from their natural counterparts - the same kind and same amount. That is to say, the ethical status of particular hybrids depends on their kinship with a being to which they are most related. For instance, a dog with a chip does not lose its moral considerability merely because it has one artificial part serving a particular goal, since this dog is still a sentient being.

The first argumentative path would be probably followed by those environmental ethicists who recognize even restored nature (e.g., forest) to be "fake" and draw a demarcation line between such objects and $100 \%$ nature. Eric Katz for instance compares the difference between the natural grown tree and the planted one to the difference between a work of art created by the original artist and a copy (Katz 
2012, pp. 70-71; see, 1993, 2002, 2018). He recognizes the autonomy of origin as an important ontological value - natural beings have this ontological value, while artifacts do not (Katz 2012, p. 72; 2002, p. 144; Ouderkirk 2002, p. 126). In a similar manner, J. Baird Callicott, who was against ascribing moral considerability to non-original members of biotic community such as farm animals, argued that they are "living artifacts, but artifacts nevertheless" and that (in reference to John Muir) they are only "half alive' in comparison with their natural and autonomous counterparts" (Callicott 1980).

Such an approach may seem to be unduly strict insofar as it limits nature to wilderness, for which it has already been criticized in environmental ethics (Brennan and Lo 2015). Seeing sentiency as a more ontologically significant feature, Singer and Regan proposed to abandon the dichotomy of wild vs. domestic in the case of animals, and instead, to grant every kind of animal the right to equal consideration. This would not, however, result in equal treatment (Singer 1989). ${ }^{9}$

We can wonder if, by the same token, it would be possible in the case of hybrids to support a thesis that moral considerability should be granted, respectively, (1) to a cow manipulated to produce a hypoallergenic milk, since it is clearly a sentient being; (2) to trees emitting light, since they are clearly beings able to grow and develop; and (3) to a river used as a power source in a factory, since it is a being belonging originally to the domain of phusis.

Yet, this solution would also reestablish the old dichotomy of nature and technology: the artificial side of beings, while giving them the added value of extra functions, is actually seen as some kind of handicap that lowers the position of hybrids in question compared to that of their fully natural counterparts. As such, it does not eliminate beings from the scope of moral considerability, but questions whether they should be brought into it. This solution above is unsatisfying because it reestablishes a strict dichotomy which is no longer valid in the case of hybrids. We believe that it would be more appropriate to revisit the very idea of instrumentality, if we wish to move beyond this binarism of nature and technology that invalidates hybrids.

When we introduced the concept of intrinsic value and defined it in terms of noninstrumentality, we underlined this as a dominant approach to this issue. There are, however, alternative views (see O'Neill 2012). The most significant is the pragmatist approach, which argues that the notion of intrinsic value understood negatively as not having any instrumental value, according to which things can possess value independently of the relations they have to other things, often suggests a peculiarly atomistic picture of the world. The complaint against instrumentality in environmental ethics, as discussed in previous sections, is that it entails a sense of domination of one being over the other. Many environmental ethicists therefore decided to drop that perspective in favor of focusing on particular beings and their intrinsic value. However, this unfortunately actually undermines environmental philosophy's attempt to convince people to recognize the interdependence of the different parts of the natural world (see McShane 2007 , p. 44). Appreciating things solely in terms of their own sake can erroneously

\footnotetext{
${ }^{9}$ This means we should include all affected interests when calculating the rightness of an action and weigh those interests equally: for instance, we need to pay equal amount of consideration when we decide whether to kill a wolf or not and when we decide if we can kill a dog, but it does not mean we need to feed a wolf like we feed our pets.
} 
result in the image of total isolation, where the organisms seem to be indifferent to each other and preoccupied solely with their own well-being. Thus, pragmatists insist on acknowledging the interrelatedness and interdependence of things (see Weston 2006, pp. 307, 312). Focusing on the instrumental value can actually bring our attention to this sense of interrelatedness and interdependence constituting a community: for instance, a forest may be valued not only for its beauty and independence from economic interests but also as a refuge for wildlife (Weston 2006, p. 311). This, we can add, does not mean that when there are no animals which need some particular tree to hide in, this tree becomes worthless. It still has its own teleology (self-development, flourishing) for which it deserves to be valued. The difference is that in such a case, some aspects of its identity (e.g., capacity to become a shelter) remain unrevealed and cannot be fulfilled.

Thus, it could be argued that the concept of intrinsic value does not exclude a more relational account. That is to say, having an intrinsic value does not necessarily lessen the significance of functional properties embedded in the network of connections between beings. However, already the terms "in-trinsic" and "in-herent" highlight the aspect of being oriented toward what is internal to these beings, evidently pushing into the background their relationality with other beings. The pragmatist approach, on the other hand, underlines that entities perceived from an environmental perspective exist primarily for each other and not merely for themselves. It highlights that we can respect and appreciate entities primarily for what they do and offer to other beings. Such a value of entities lies beyond the value they have for human interests and are not necessarily contaminated by power relations (see Hargrove 2012, pp. 178, 179). In what follows, building upon this criticism, we therefore propose the concept of "functional value" and show why it is of crucial importance for hybrids.

First, it is worth elucidating some semantic differences between the terms "instrumental" and "functional." While they are basically synonyms, they have quite different rhetoric connotations: "instrumental" is a rather pejorative epithet referring to reducing a thing to a means to something else's goals. "Functional," on the other hand, is neutral or even positive. This adjective indicates the quality of being "practical," "useful," or "capable of operating and functioning", as well as "capable of serving the purpose for which it was designed" (Thesaurus 2019). Such a definition correlates obviously with the definition of function, which dates back to sixteenth century Middle French, in which it meant "one's proper work or purpose; power of acting in a specific proper way." It derives directly from the Latin functionem (nominative functio) - "a performance, an execution." The verb funct- (past participle stem of fungi), meaning "perform, execute, discharge," can be in turn traced to Proto-Indo-European language *bhung - "be of use, be used." Interestingly, it is also the source of Sanskrit bhunjate - "to benefit, make benefit, atone," Armenian bowcanem - "to feed,' and Old Irish bongaid - "to break, harvest," which is perhaps related to the root *bhrug"to enjoy" (Etymonline 2019).

In accordance with these etymological-lexicographical considerations, "functional" can be defined as "acting purposely for some benefit." This is in line with a biological use of the term "function" which usually refers to the capacities of an organism or its smaller parts (organs, cells, etc.) that are necessary to survive and reproduce (Garson 2016, pp. 1-2). Such a framing of functions is significantly different from the case of technological objects (instruments). In the latter, premium is put on that they are merely 
means to some ends, while when we think of functions in a "biological" way, there is no such strong sense of subordination.

Thus, we suggest to employ the term "functional value" in order to avoid the negative semantic connotations of the instrumentality. In doing so, we are not making a purely terminological shift. Functional value seeks to challenge the binarism of an instrumental value (as related to mercantile, short-term profits) and an intrinsic value. What is of functional value can be valued for the way it is. It (if we were to use Heideggerean terminology) can be disclosed thanks to participating in the network of things, their relationality, and dependency. ${ }^{10}$ The point is to think differently about functions: we need to drop the perspective of subordination and focus on its contribution to other individuals and/or the common good. An obstacle to this is grounded in our reluctance to treat human beings "instrumentally," that is as means and not as ends in themselves. The concept of functional value, by redefining what it means to serve a function, aims to go beyond such a framing. We intend to show that functions are not necessarily entangled in relations of power and violence, but with serving the needs and providing support to others. Functionality thought this way calls for respect and reverence. As such, it can have significant consequences for the scope of moral considerability, since it frames the act of benefitting other beings as morally valuable. This leads to the question: what are the purposes of hybrids and who or what benefits from them?

Take as an example of a hybrid an artificial coral reef. It is a biomimetic construction that follows the design of regular coral reef (Chen et al. 2015). An artificial coral reef is created to sustain the biodiversity ${ }^{11}$ and stop the erosion of the coasts. It starts artificially and enables the growth of a natural coral reef, so even though they are deliberately manmade structures, they are neither serving exclusively human goals nor exploiting the planet—but instead, purposely contributing to the good of other beings and the entire environment.

The fact that other beings can benefit from (the functionality of) these hybrids does not make the latter metaphysically and ethically inferior - there is no real reason to see it through that negative lens. Natural coral reef has been destroyed and will take thousands of years to recover, but with the help of hybrids, it can recover much faster (Ammar 2009). This shows how functionality should not be seen through the lens of subordination and domination, but rather through the lens of support. We need to alter the image of the ecosystem as a hierarchical, vertical structure to a more horizontal structure: it is rather a network than a ladder - a network within which all beings mutually offer their own potential, via their function, to other beings. Thus, we argue we need to see functionality as a feature that qualifies to be included in the domain of moral considerability.

Such an approach - perceiving nature as a network and interdependent function as a kind of contribution to the common good and good of others-echoes the very origins of environmental ethics, which we have already mentioned here, namely "land ethic": a thing is right when it tends to preserve the integrity, stability, and beauty of biotic community, but it

\footnotetext{
${ }^{10}$ Such a perspective could be matched to mindfulness-based approach, which advocates relating to our tools and other mundane objects in our life with respect and reverence, aiming to avoid an instrumentalist stance, and, furthermore, leads to the cultivation of an appreciation of nature as an interconnected whole.

${ }^{11}$ But it also boosts tourism because it attracts SCUBA divers. The question is which intentions are primary?
} 
is wrong when it tends otherwise. In our view, this ethic sheds light on the relatedness of all beings in the environment, which act and function by supporting each other. We accentuate the interdependency of all components of the environment emerging today: natural, artificial, and hybrid. Such an orientation does not necessarily need to have "totalitarian" implications like subordinating one's own interests completely for the sake of "greater good," which is often how the holistic view is described (Marietta 2003, p. 125). Functional interdependency can instead be seen as the possibility to contribute to the common good of the ecosystem as well as to disclose the full variety of aspects of a being's identity that are not limited solely to their self-centered end or telos.

The problem with the classical reading of "land ethic" is the boundaries of community. Its restriction to the wild elements of an ecosystem ${ }^{12}$ can no longer be valid in current times. ${ }^{13}$ Phrases such as "living artifacts" or "half alive" gain completely new meanings in the context of hybrids - they are no longer metaphorical, but actually literal, which demands more cautious use of the terms. We therefore advocate extending the community we take into moral consideration on the basis of its ability to make a contribution to the sustainable development of that community. We embrace the idea of functional value that crosses the boundaries of naturalness and artificiality with which it is currently identified. The criterion for moral considerability as the contribution to a sustainable future cannot be narrowed to the category of eco-efficiency so profitable to humans, but is supposed to take interests of non-human beings seriously. The example of the coral reef should show it clearly: it is not some short-term economic interest that is at stake, but the long-term stability of the existence of the ecosystem of which human beings are a part. Hybrids tend to maintain non-human elements of the environment in good shape or even improve its current condition. This description also applies to biorefineries, biosatellites, ecological buildings, and so forth.

The last issue, but by far not the least, consists namely of the hybrids whose functions are related primarily to human needs, for instance the aforementioned cow producing hypoallergenic milk. Do such hybrids also deserve moral considerability based on their contribution to the good of the ecosystem? The answer depends on how we perceive human beings. Referring to Aldo Leopold's famous saying that "they are plain citizens of the Earth", we can formulate two possible responses. One is that human beings as plain citizens do not have any privileges and therefore, nothing justifies our exploitation of the planet. Hence, hybrids that prioritize human needs to the detriment of other beings should not be granted moral considerability. On the other hand, however, insofar as human beings are citizens of the planet, their needs have to be fulfilled as much the needs of non-human beings. This is not a justification of the polluting of the planet and excessive consumption of natural resources; it is merely an attempt to avoid misanthropy. Thus, we can claim that hybrids are morally considerable to the extent that they are conditional for the flourishing of the human species and at the same time do not interfere with the conditions for the flourishing of non-human beings in the same ecosystem.

\footnotetext{
${ }^{12}$ Callicott distances himself from the idea of preserving "wilderness," and later made use of the concept of "biosphere reserves" (Callicott 2006, p. 440).

${ }^{13}$ More sympathetic reading of Leopold's work can however point that his remark Odysseus hanging his slave girls shows that he put some ethical restrictions to beings of instrumental vale, assuming that even when something is our property this does not allow us to do anything we wish with it (see Gunkel and Bryson 2014, p. 6).
} 


\section{Conclusions}

Environmental ethics was the first field to discuss the issue of the moral considerability of non-human beings. The debate over moral considerability's scope revolves around the point whether an organism has a specific, individual good of its own - whether it be freedom from pain, non-interfered growth, or undisturbed existence-which is not subordinated to goals of other beings (referred to as having "intrinsic value"). Traditionally, moral considerability can be granted only to beings capable of having such a value. We suggest to revise the scope of moral considerability by redefining the concept of intrinsic value as non-instrumental value. We argue that it is primarily the ability to serve other beings by performing certain of their functions that belong to their identity, which should qualify a being to have moral considerability. That is to say, it is its contribution to the common good of the ecosystem, and thereby to the good of other individual beings, which deserves moral respect and consequently moral considerability. In order to avoid the negative connotation of "instrumentality," we propose to speak of "functional value." This is not however merely a terminological shift. The concept of functional value seeks to challenge the binarism of an instrumental value (as oriented toward mercantile, short-term profits) and an intrinsic value (as being solely oriented toward individual good).

This recognition of function (ality) challenges the strong opposition between the ethical status of natural beings and that of artifacts, which is of crucial importance for hybrids, which constitute a third ontological category. They are designed very precisely for specific purposes and created by human beings but their functions are not solely oriented toward human economic goals, but can serve the entire ecosystem. We argue that this qualify hybrids to the scope of moral considerability.

The case of hybrids shows that technology should no longer be seen as purely detrimental, with no positive aspects. Technology can serve good purposes, seen from the environmental perspective: human (anthropos) agency, from which the current epoch-Anthropocene - derives its name, is not oriented solely to the excessive use of natural resources and ruinous introduction of new elements to the atmosphere and biosphere, but has also begun to take responsibility for Earth's sustainability (Blok 2017). This can be seen as a hallmark of the third - current-phase of the Anthropocene. ${ }^{14}$

Hybrids will definitely play an important role in the future development of our planet. This paper merely sketches the grounds of the debate regarding their ethical status. To map this terrain in more detail, we will need to answer further questions. First group of questions will need some help of more applied philosophers. For instance, how to solve the conflict between the interests of two different organisms: one regular ("natural") and one bio-augmented? Which one should be prioritized? When being "natural" stops being the determinant of what is worth moral care, the answer is neither obvious nor simple. In any case, we will certainly need to temper our urge to contribute positively to the sustainable development of the Earth with the recognition that there is still much we do not know about nature.

\footnotetext{
${ }^{14}$ The period of the Anthropocene is generally assumed to start during the industrial revolution (1st phase), accelerating after the World War II (2nd phase), and will end in our current situation in which the Earth's existence is threated due to climate change (3rd phase).
} 
But the idea of functional value leaves the door open to grant moral considerability to artifacts, which are not one homogeneous set. ${ }^{15}$ It can start with the extended analysis of AI (due to their specific capacities), which shall be merged with ongoing discussions on the moral status and agency of robots and other intelligent systems. The concept of functional value approached from this angle will be also inseparable from the issue of human enhancement and its ethical assessment due to such problems as human agency, identity, and responsibility.

Fears that we must fight when dealing with hybrids and functional value are basically two: technophobia and anthropophobia, which are closely related when employing an ecological perspective. No one can deny that human intervention in the ecosystem via technological means can have wide-scale negative effects. But neither we can deny that human beings are a part of the ecosystem which is their habitat. Following the misanthropy way is not the solution to the ecological crisis. The lesson learned from the rugged pathway of such movements as deep ecology shows that it can only turn against their efforts. Thus, our attitude toward technologies should not be simply hostile but rather complex and nuanced.

Funding Information This research was supported by the grant DIALOG 0023/2019 from the Ministry of Science and Higher Education (Poland).

Open Access This article is distributed under the terms of the Creative Commons Attribution 4.0 International License (http://creativecommons.org/licenses/by/4.0/), which permits unrestricted use, distribution, and reproduction in any medium, provided you give appropriate credit to the original author(s) and the source, provide a link to the Creative Commons license, and indicate if changes were made.

\section{References}

Ammar, M. S. A. (2009). Coral reef restoration and artificial reef management, future and economic. The Open Environmental Engineering Journal, 2, 37-49.

Annila, A., \& Kolehmainen, E. (2015). On the divide between animate and inanimate. Journal of Systems Chemistry, 6(1), 2. https://doi.org/10.1186/s13322-015-0008-8. Accessed 01 Mar 2019.

Avella, M., et al. (2005). Biodegradable starch/clay nanocomposite films for food packaging applications. Food Chemistry, 93, 467-474.

Baker, L. R. (2009). The metaphysics of everyday life. Cambridge: Cambridge UP.

Benyus, J. (2002). Biomimicry: innovation inspired by nature. New York: Harper Perennial.

Birch, T. (1993). Moral considerability and universal consideration. Environmental Ethics, 15(4), 313-332.

Blok, V. (2017). Earthing technology: towards an eco-centric concept of biomimetic technologies in the Anthropocene. Techné: Research in Philosophy and Technology, 21(2-3), 127-149.

Blok, V., \& Gremmen, B. (2016). Ecological innovation: biomimicry as a new way of thinking and acting ecologically. Journal of Agricultural and Environmental Ethics, 29(2), 203-217.

Brennan, A. (1984). The moral standing of natural objects. Environmental Ethics, 6(1), 35-56.

Brennan, A. (1988). Thinking about nature. An investigation of nature, value and ecology. Athens: The University of Georgia Press.

\footnotetext{
15 There are possible other argumentative strategies for ascribing moral considerability to artifacts. For instance, one might say that artifacts should be given moral consideration as the product of concentrated labor and ingenuity of natural beings - namely humans. Another criterion can be being a unique and irreplaceable individual (see Holy-Luczaj 2020).
} 
Brennan, A., \& Lo, S. Y. (2010). Understanding movements in modern thought: understanding environmental philosophy. Durham: Acumen Publishing.

Brennan, A. Lo S.-Y. (2015). Wilderness, the built environment, poverty and politics. Entry in Stanford Encyclopedia of Philosophy. https://plato.stanford.edu/entries/ethics-environmental/\#WilBuiEnvPovPol. Accessed 01 Mar 2019.

Callicott, J. B. (1980). Animal liberation: A triangular affair. Environmental Ethics, 2(1980), 311-328.

Callicott, J. B. (1986). The metaphysical implications of ecology. Environmental Ethics, 8(4), 301-316.

Callicott, J. B. (1988). Agroecology in context. Journal of Agricultural Ethics, 1(1988), 3-9.

Callicott, J. B. (2005). The pragmatic power and promise of theoretical environmental ethics: Forging a new discourse. In A. W. Galston \& C. Z. Peppard (Eds.), Expanding Horizons in Bioethics (pp. 185-208). Dordrecht: Springer.

Chen, D., Ross, B., \& Klotz, L. (2015). Lessons from a coral reef: biomimicry for structural engineers. Journal of Structural Engineering, 141(4), 02514002 http://citeseerx.ist.psu.edu/viewdoc/download?doi=10.1.1.709.88 \&rep=rep1\&type=pdf. Accessed 01 Mar 2019.

Devall, B. (1995). The ecological self. In A. Drengson \& Y. Inoue (Eds.), The deep ecology movement: An introductory anthology. Berkeley: North Atlantic Books.

Dicks, H. (2016). The philosophy of biomimicry. Philosophy and Technology, 29(3), 223-243.

Dicks, H. (2017). Environmental ethics and biomimetic ethics: nature as object of ethics and nature as source of ethics. Journal of Agricultural and Environmental Ethics, 30(2), 255-274.

Etymonline (2019) entry: "Function", https://www.etymonline.com/word/function. Accessed 01 Mar 2019.

Floridi, L. (2008). Information ethics, its nature and scope. In J. van den Hoven \& J. Weckert (Eds.), Information technology and moral philosophy (pp. 40-65). Cambridge: Cambridge University Press.

Floridi, L. (2013). The ethics of information. Oxford: Oxford University Press.

Franssen, M. (2008). Design, use, and the physical and intentional aspects of technical artifacts. In P. E. Vermaas et al. (Eds.), Philosophy and Design. From Engineering to Architecture (pp. 21-22). Dordrecht: Springer.

Garson, J. (2016). A critical overview of biological functions. Dordrecht: Springer.

Goodpaster, K. (1978). On being morally considerable. Journal of Philosophy, 75(6), 310-311.

Goodpaster, K. (1980). On stopping at everything. Environmental Ethics, 2(3), 281-284.

Gunkel, D. (2012). The machine question critical perspectives on AI, robots, and ethics. Cambridge: MIT Press.

Gunkel, D. (2014). A vindication of the rights of machines. Philosophy \& Technology, 27(1), 113-132.

Gunkel, D., \& Bryson, J. (2014). Introduction to the special issue on machine morality: the machine as moral agent and patient. Philosophy \& Technology, 27(1), 5-8.

Hale, B. (2011). Moral considerability: deontological, not metaphysical. Ethics \& the Environment, 16(2), 3762.

Hargrove, E. (2012). Weak anthropocentric intrinsic value. In A. Light \& H. Rolston III (Eds.), Environmental ethics. An anthology. Malden (MA): Blackwell Publishing.

Holy-Luczaj, M. (2020). Artifacts and the limitations of moral considerability. Environmental Ethics, 41(1), 69-87.

Holy-Luczaj, M., \& Blok, V. (2019). How to deal with hybrids in the anthropocene? Towards a philosophy of technology and environmental philosophy 2.0 (with Vincent Blok). Environmental Values, 28(3), 325345.

Horta, O. (2018). Moral considerability and the argument from relevance. Journal of Agricultural and Environmental Ethics, 31(3), 369-388.

Houkes, W., \& Vermaas, P. E. (2009). Produced to use: combining two key intuitions on the nature of artefacts. Techne: Research in Philosophy and Technology, 13(2), 123-136.

Howe, L. W. (1993). The metaphysical turn in environmental philosophy. Between the Species, 4, 9-15.

Katz, E. (1993). Artefacts and functions: a note on the value of nature. Environmental Values, 2(3), $223-232$.

Katz, E. (2002). Understanding moral limits in the duality of artifacts and nature: a reply to critics. Ethics \& the Environment, 7(1), 138-146.

Katz, E. (2012). Further adventures in the case against restoration. Environmental Ethics, 34(1), 67-97.

Katz, E. (2018). Replacement and irreversibility: the problem with ecological restoration as moral repair. Ethics \& the Environment, 23(1), 17-28.

Kingsbury, N. (2009). Hybrid. The history and science of plant breeding. Chicago: The Chicago University Press.

Krichevsky, A., Meyers, B., Vainstein, A., Maliga, P., \& Citovsky, V. (2010). Autoluminescent plants. PLoS One, 5(11), e15461. Published 2010 Nov 12. https://doi.org/10.1371/journal.pone.0015461. 
Kroes, P., \& Vermaas, P. E. (2008). Interesting differences between artifacts and natural objects. APA Newsletter, 8(1), 28-31.

Lawson, C. (2008). An ontology of technology: Artefacts, relations and functions. Techné, 12(1), 48-64.

Lee, K. (1999). The Natural and the Artefactual. The implications of deep science and deep technology for environmental philosophy. Lanham: Lexington Books.

Leopold, A. (1987). The land ethic. In A. Leopold (Ed.), A sand county almanac: and sketches here and there. Oxford: Oxford UP.

Light, A. (2009). Faking art and faking nature: The art analogy and restoration ecology. Cybergeo: European Journal of Geography. Dossiers, Esthétique et environnement, document 480, mis en ligne le 14 décembre: 1-14. http://cybergeo.revues.org/index22275.html.

Light, A., \& Holmes Rolston, I. I. I. (2006). Introduction: ethics and environmental ethics. In A. Light \& H. Rolston III (Eds.), Environmental ethics. An anthology. Malden (MA): Blackwell Publishing.

Marietta Jr., D. E. (2003). Back to earth with reflection and ecology. In C. S. Brown \& T. Toadvine (Eds.), Eco-phenomeneology: Back to the eart itself (pp. 51-72). Albany: SUNY.

McShane, K. (2007). Why environmental ethics shouldn't give up on intrinsic value. Environmental Ethics, 29(1), 43-61.

Murray, H. W. (1980). Are mere things morally considerable? Environmental Ethics, 2(3), 59-65.

Naess, A. (1984). Intuition, intrinsic vales and deep ecology. The Ecologist, 14(5/6), 2013-2203.

Naess, A., \& Sessions, G. (1995). Platofrm principles of the deep ecology movement. In A. Drengson \& Y. Inoue (Eds.), The deep ecology movement. An introductory anthology. Berkeley: North Atlantic Books.

O'Neill, J. (2012). The varieties of intrinsic value. In A. Light \& H. Rolston III (Eds.), Environmental Ethics. An Anthology. Malden: Blackwell Publishing.

Ouderkirk, W. (2002). Katz's problematic dualism and its "seismic" effects on his theory. Ethics \& the Environment, 7(1), 124-137.

Peterson, M. J.; Sandler, R. (2008). Ethical evaluation of new technologies: genetically modified organisms and plants. International dimensions of ethics education case study series, available at: https://scholarworks.umass.edu/edethicsinscience/36/. Accessed 01 Mar 2019.

Rajeshwar, K. (2012). Biomimetic or bioinspired? Editor's note. The interface, available at https://www. electrochem.org/dl/interface/fal/fal12/fal_win12_p003.pdf. Accessed 01 Mar 2019.

Regan, T. (1983). The case for animal rights. Berkeley: University of California Press.

Robaey, Z. (2016). Transferring moral responsibility for technological hazards: the case of GMOs in agriculture. Journal of Agricultural and Environmental Ethics, 29(5), 767-786.

Siipi, H. (2003). Artefacts and living artefacts. Environmental Values, 12(4), 413-430.

Singer, P. (1975). Animal liberation: a new ethics for our treatment of animals. New York: Avon.

Singer, P. (1989). All animals are equal. In: T. Regan and Peter Singer (eds.), Animal Rights and Human Obligations. New Jersey: Prentice-Hall, 1989, 148-162.

Taylor, P. (1986). Respect for nature. Princeton UP: Princeton.

Thesaurus (2019) entry "functional", https://www.dictionary.com/browse/functional. Accessed 01 Mar 2019.

Thomson, I. (2004). Ontology and ethics at the intersection of phenomenology and environmental philosophy. Inquiry, 47(4), 380-412.

Torrance, S. (2008). Ethics and consciousness in artificial agents. AI \& SOCIETY, 22, 495-521.

Van Acker, R., Rahman, M., Cici, S. (2017). Pros and cons of GMO crop farming. Oxford Research Encyclopedia of Environmental Science, available at: http://environmentalscience.oxfordre. com/view/10.1093/acrefore/9780199389414.001.0001/acrefore-9780199389414-e-217.

Vogel, S. (2003). The nature of artifacts. Environmental Ethics, 25(2), 149-168.

Vogel, S. (2015). Thinking like a mall. Cambridge: MIT Press.

Weston, A. (1996). Beyond intrinsic value: Pragmatism in environmental ethics. In E. Katz (Ed.), Environmental Pragmatism, A. Light (pp. 285-306). London.

Xu, C., Hu, S., \& Chen, X. (2016). Artificial cells: from basic science to applications. Materials Today, 19(9), 516-532.

Zimmerman M. (2014). Intrinsic vs. extrinsic value. Entry in Stanford Encyclopedia of Philosophy, https://plato.stanford.edu/entries/value-intrinsic-extrinsic/.

Publisher's Note Springer Nature remains neutral with regard to jurisdictional claims in published maps and institutional affiliations. 